\title{
Research Paper \\ Dropout in Outpatient Psychiatric Clinic, Roozbeh Hospital: One Year Follow-Up
}

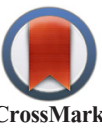

*Zahra Mirsepassi ${ }^{1}$, Javad Alaghband Rad ${ }^{2}$, Vandad Sharifi ${ }^{3}$, Valentine Artounian ${ }^{1}$, Parvaneh Farhad Beigi ${ }^{4}$, Fattaneh Abdi ${ }^{5}$, Omran Mohammad Razaghi ${ }^{3}$, Hamidreza Naghavi ${ }^{1}$, Homayoun Amini ${ }^{6}$, Sara Jafari ${ }^{7}$

1. Psychiatrist, Assistant Professor, Department of Psychiatry, School of Medicine, Tehran University of Medical Sciences, Tehran, Iran

2. Child and Adolescent Psychiatrist, Associate Professor, School of Medicine, Tehran University of Medical Sciences, Tehran, Iran.

3. Psychiatrist, Associate Professor, Department of Psychiatry, School of Medicine, Tehran University of Medical Sciences, Tehran, Iran.

4. MSc., Cognitive Psychology, Institute for Cognitive Science Studies, Tehran, Iran.

5. MSc., Department of Psychiatry, School of Medicine, Tehran University of Medical Sciences, Tehran, Iran.

6. Psychiatrist, Professor, Psychosomatic Research Center, Tehran University of Medical Sciences, Tehran, Iran.

7. Psychiatrist, Department of Psychiatry, School of Medicine, Tehran University of Medical Sciences, Tehran, Iran

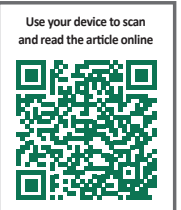

CFtation: Mirsepassi Z, Alaghband Rad J, Sharifi V, Artounian V, Farhad Beigi P, Abdi F, et al. [Dropout in Outpatient Psychiatric Clinic, Roozbeh Hospital: One Year Follow-Up (Persian)]. Iranian Journal of Psychiatry \& Clinical Psychology. 2017; 22(4):330-339. https://doi.org/10.18869/nirp.ijpcp.22.4.348

doi: : https://doi.org/10.18869/nirp.ijpcp.22.4.348

Received: 04 Aug. 2016 Accepted: 15 Nov. 2016

Keywords: Dropout, Continuity of care, Outpatient, Psychiatric clinic

\section{ABSTRACT}

Objectives Mental illnesses are common among outpatient clinics, but only some of these patients receive adequate treatments and attend. The purpose of this study is to evaluate the dropout rate and identify the predictors of dropouts in outpatient clinics in Roozbeh Psychiatric Hospital.

Methods A questionnaire designed by expert psychiatrists was filled. The questionnaire consists of information collected from medical records of 400 patients who consulted outpatient clinics of Roozbeh Psychiatric Hospital. The data were analyzed using SPSS16.

Results The total dropout rate was 57.8\% (males: $33.5 \%$ and females: $24.3 \%$ ). The dropout rates in adult and child and adolescent clinics were $58 \%$ and $43.8 \%$, respectively. A total of $11 \%$ of total dropout rate was in patients under 18 years, $41.8 \%$ was in patients aged 18 to 65 years, and $5 \%$ was in patients aged 65 years and over. There were significant relationships between drop out rate and variables of patients' age, educational degrees, occupation, referral point, and type of diagnosis. However, no significant relationships were found between drop out rate and gender or marital status of the patients.

Conclusions Dropout is a common barrier in delivering outpatient psychiatric treatments. There need to be proper interventions to reduce such dropouts.

\section{* Corresponding Author:}

Zahra Mirsepassi, MD

Address: Department of Psychiatry, School of Medicine, Tehran University of Medical Sciences, Tehran, Iran.

Tel: +98 (21) 55412222

E-mail: z-mirsepassi@sina.tums.ac.ir 


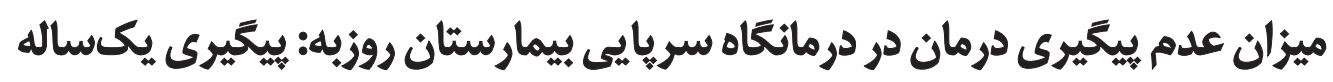

"زهرا ميرسياسى'، جواد علاقبندرادّ، ونداد شريفى'، والنتين آرتونيان'، يروانه فرهادييكى '، فتانه عبدى ماسوله'، عمران محمدرزاقى"،

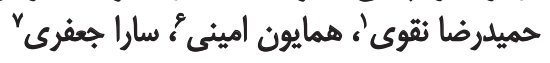

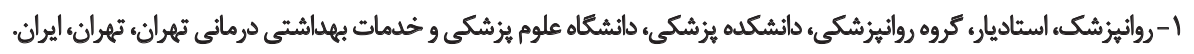

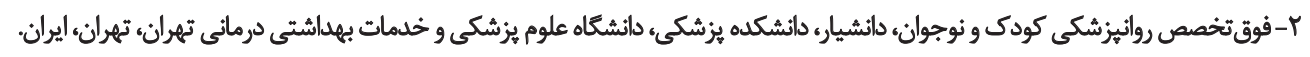

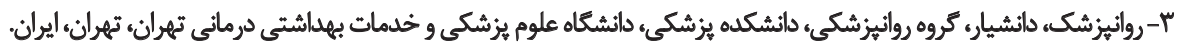

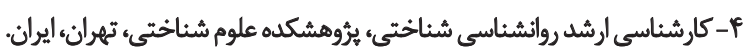

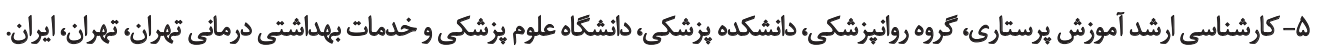

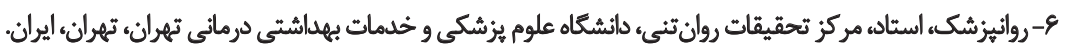

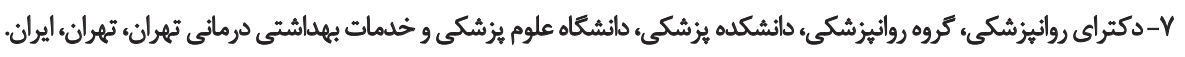

\footnotetext{
حكبد

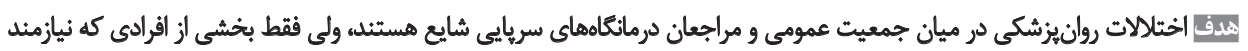

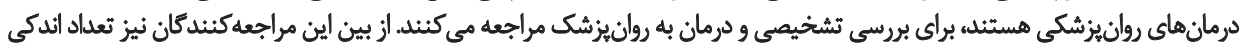

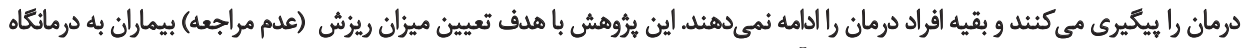

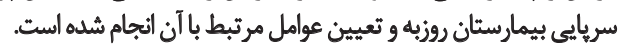

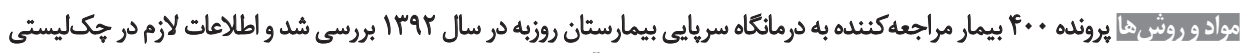

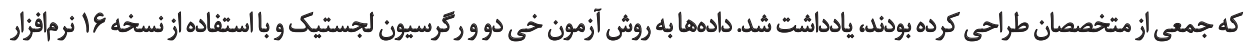
Spss

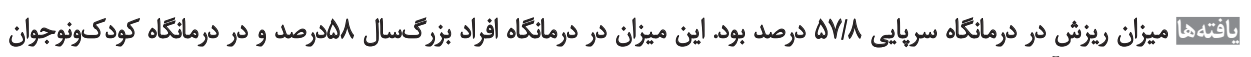

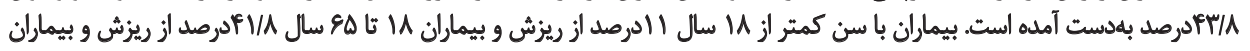

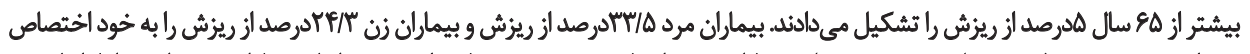

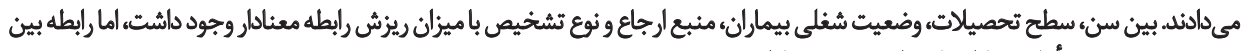

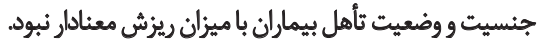

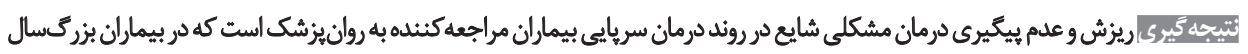

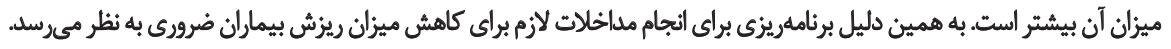

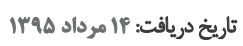

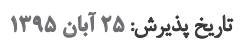

كليدوأزه

دريزش، عدم مراجعه، درمانتاه سريايى مراجي دوانيزشكى

تحميل مى كنئد. با وجود اين، تنها بخشى از افرادى كه نيازمند

dole

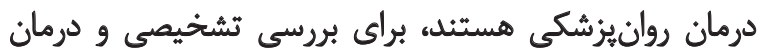

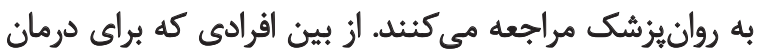

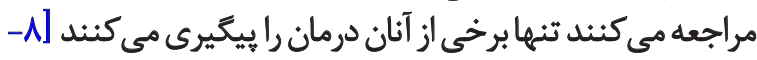

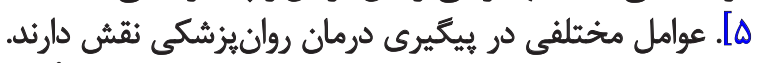

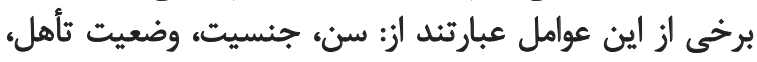

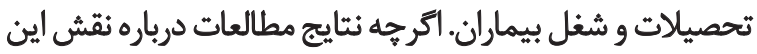

$$
\text { عوامل يكسان نبوده است [عات 19-9]. }
$$

شناسايى ويرگى هاى مؤثر در عدم بيكيرى درمان بايد مدنظر

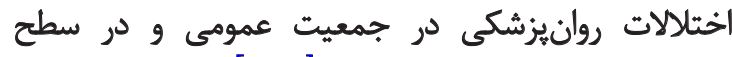

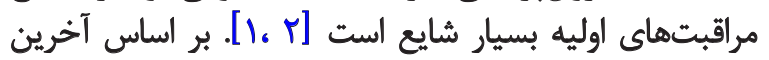

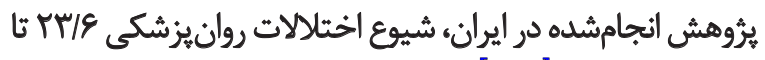

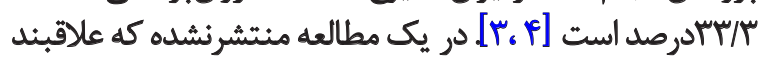

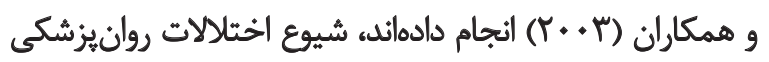

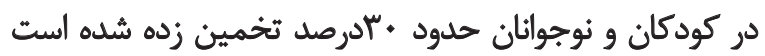

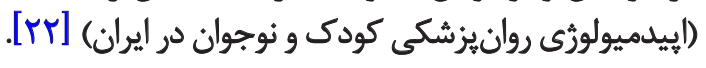
اين اختلالات هزينههاى مستقيم و غيرمستقيمى بر جامعه 


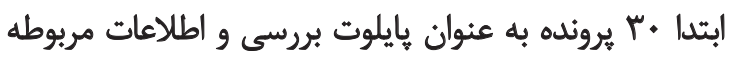

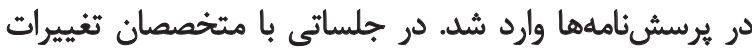

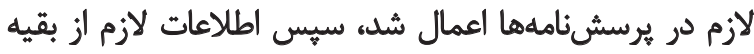

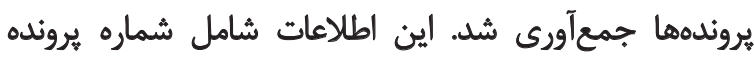

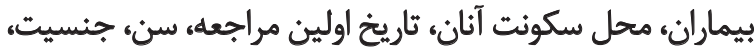

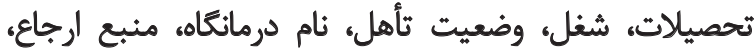

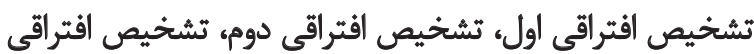

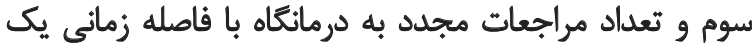

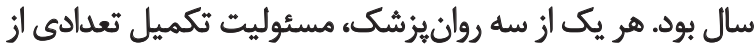

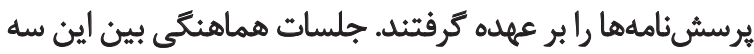

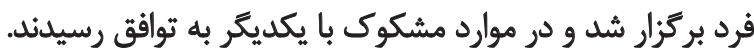

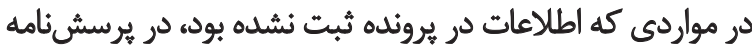

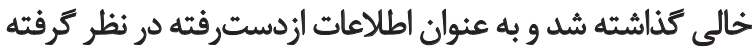

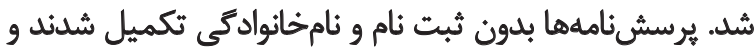

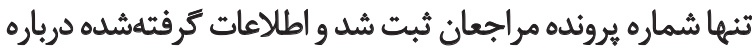
هر فرد به صورت محرمانه باقى ماند.

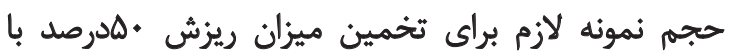

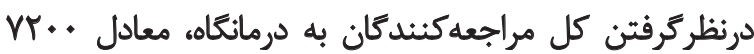

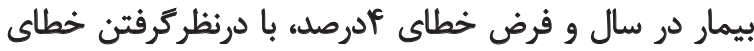

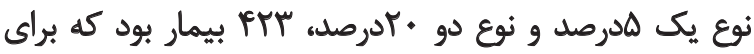

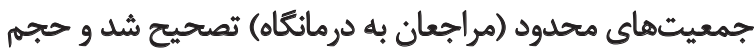

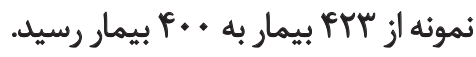

آمارهاى توصيفى ازجمله يافتن درصد و ميانكين بيماران در هر

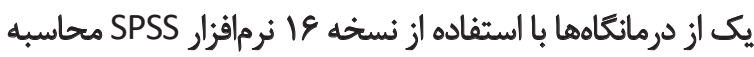

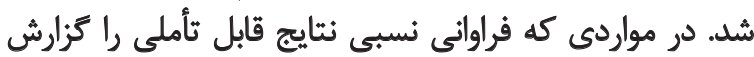

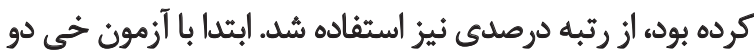

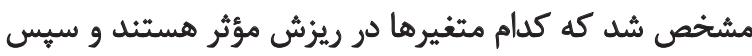

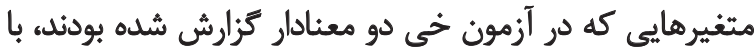
روش ركرسيون لجستيك بررسى شدند. سطح معنادارى عنوان سطح قابل ورود به تحليل در نظر كرفته شد.

ياثتهها

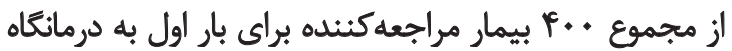

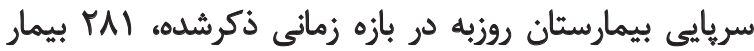

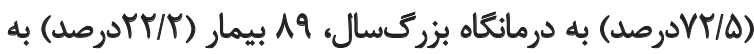

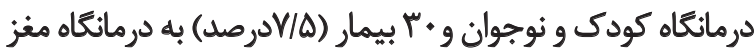

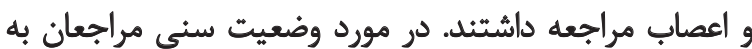

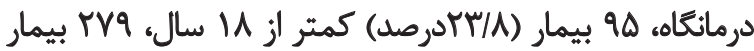
(Q

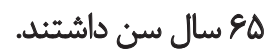

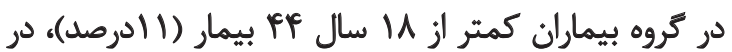

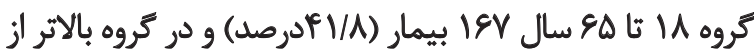

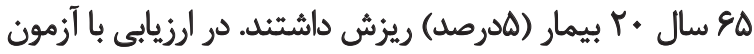

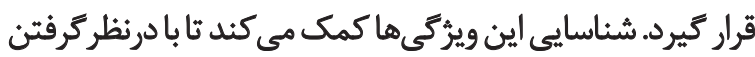

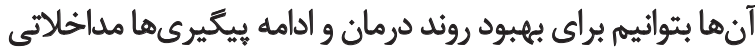

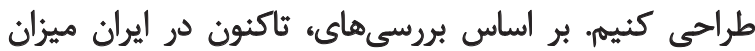

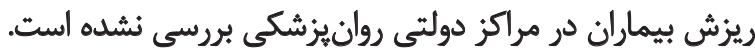

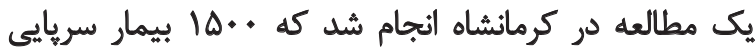

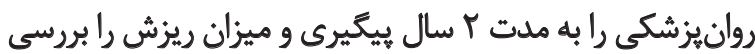

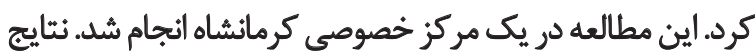

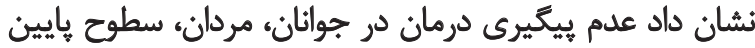

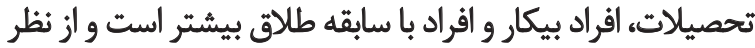

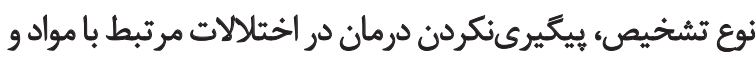

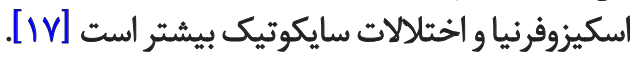

بررسى يُيكيرى درمان در بيمار ان مراجعه كنثنه به يك درمانكاه

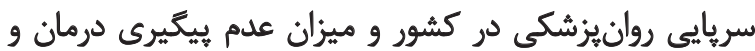

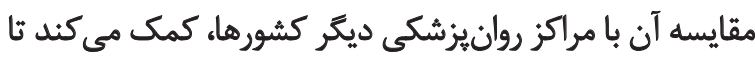

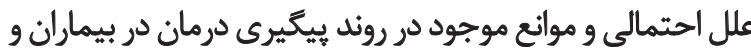
تفاوتهاي احتمالى آن را با مراكز كشورهاي ديكر دريابيمي.

קوش

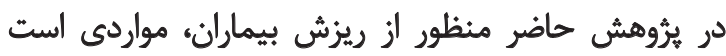

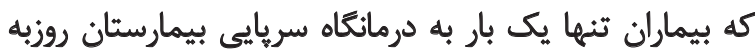

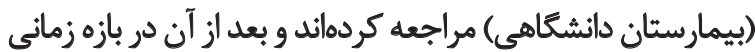

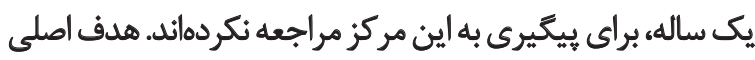

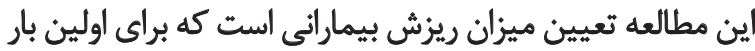

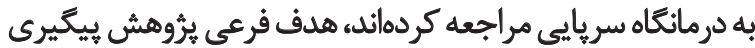
يكساله و تعيين عوامل مرثبط با باين ريزش است

بيمارستان روزبه درمانكاههاى روانيزشكى بزركسال، كودى

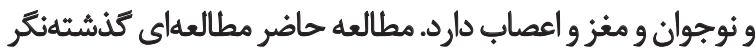

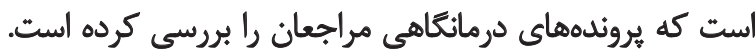

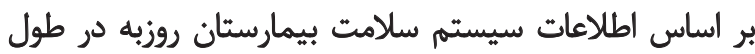

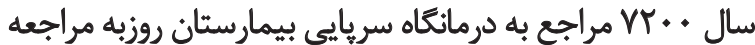

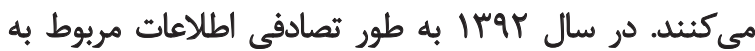

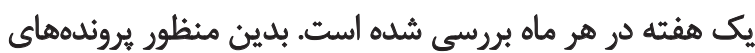

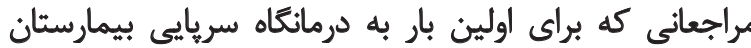

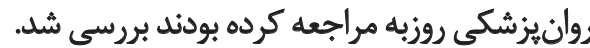

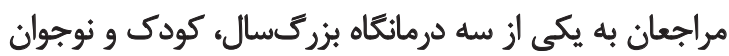

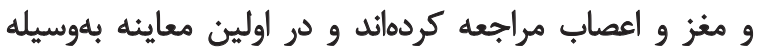
روانيزشك يا متخصص مغز و واعصاب (عضو هيئت علمى ئي يا كادر

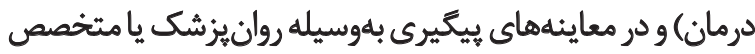

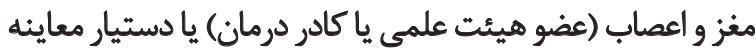

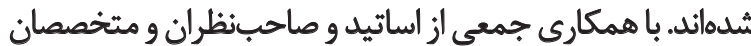

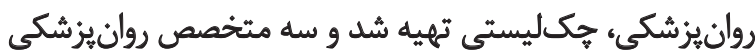
يروندها و ابزارها را بررسى كردند. 


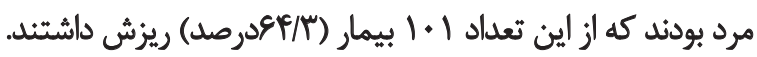

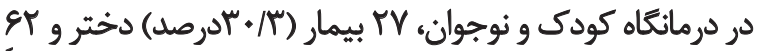

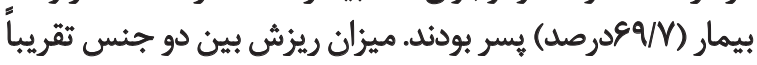

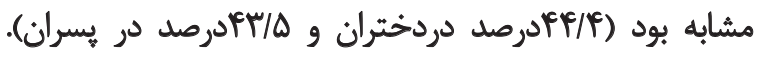
رابطه جنسيت با ريزش معنادار نبود (df=1، P=×/fVV).

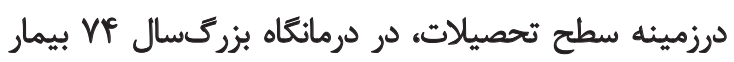

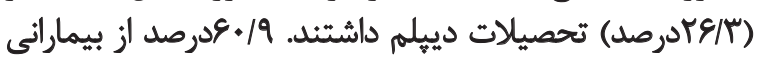

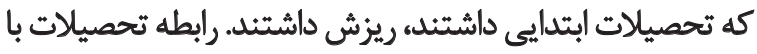

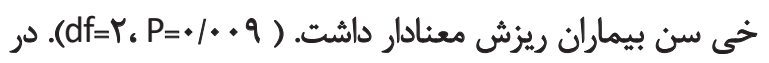

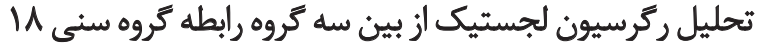

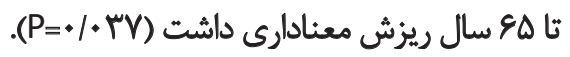

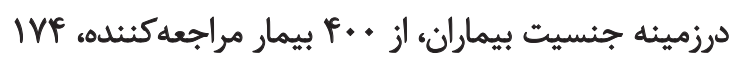

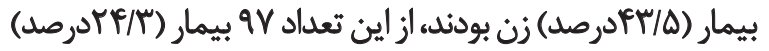

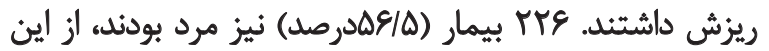

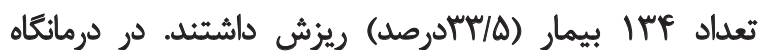

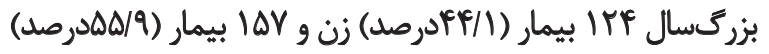

جدول ا. ويثُى هاي دموكرافيك بيماران مراجعه كثنده به درمانكاه بيمارستان روزبه.

\begin{tabular}{|c|c|c|}
\hline تعداد & كروه & متغير \\
\hline $9 \Delta$ & زير مل سال & \multirow{3}{*}{ سن سن } \\
\hline rqa & A 1A-1 & \\
\hline re & بالاتر از هو سال & \\
\hline rYE & مذكر & \multirow{2}{*}{ جنس } \\
\hline ine & مونث & \\
\hline rt & بي سواد & \multirow{5}{*}{ تحصيلات } \\
\hline$\Delta \Delta$ & بينجم دبستان & \\
\hline av & سيكل سل & \\
\hline$\wedge 1$ & دييلم & \\
\hline q & تحصيلات دائشكاهى & \\
\hline$\Lambda$ & بيكار & \multirow{7}{*}{ شغل } \\
\hline ru & كارمند & \\
\hline$\mu$ & شغل آزاد & \\
\hline १ศ & خانهدار & \\
\hline if & كارئر & \\
\hline$M$ & بازنشسته & \\
\hline IV & دانشجو & \\
\hline 114 & هجرد | لمجر & \multirow{4}{*}{ وضعيت تاهل } \\
\hline v & متاركه كرده & \\
\hline 1 & بيوه & \\
\hline DAT & متاهل & \\
\hline 「A) & شهر تهران & \multirow{4}{*}{ محل سكونت } \\
\hline$\Delta F$ & استان تهران & \\
\hline af & ديكر استانها & \\
\hline 1 & نامشخص & \\
\hline
\end{tabular}


جدول r. منيع ارجاع بيماران در درمائكاه بزركسال و كودى و نوجوان بيمارستان روزبه.

\begin{tabular}{|c|c|c|c|c|}
\hline \multicolumn{2}{|c|}{ درمانكاه كودك و نوجوان } & \multicolumn{2}{|c|}{ درمانكاه بزركىسال } & \multirow{2}{*}{ منبع ارجاع } \\
\hline درصد & تعداد & درصد & تعداد & \\
\hline$V E / F$ & gA & $g \& / r$ & $W^{C}$ & خود بيمار و خانواده \\
\hline$r \cdot$ & M & $r \cdot / r^{\circ}$ & $\Delta V$ & | بز شكان \\
\hline - & • & $V / \Delta$ & $M$ & ييمهها| \\
\hline • & - & $\cdot / V$ & r & نيروى انتظامى \\
\hline$r / r$ & r & $r / \Delta$ & $\checkmark$ & يز شكى قانونى \\
\hline M & 1 & $r /$ & 8 & نظاموظيفه \\
\hline
\end{tabular}

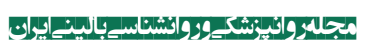

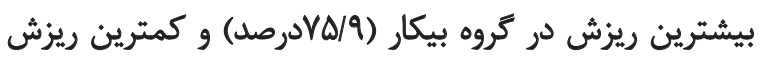

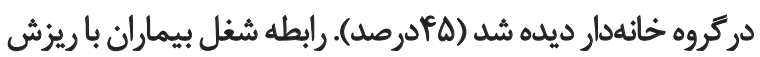

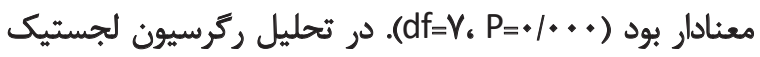

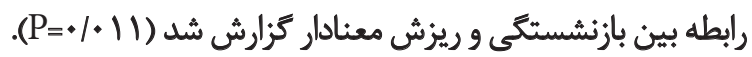

درزمينه وضعيت تأهل، از بين بN بين بيمار مراجعلكنئده به

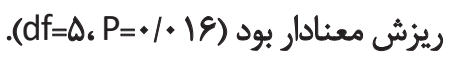

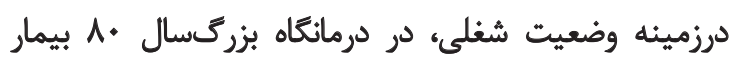

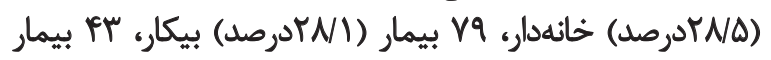

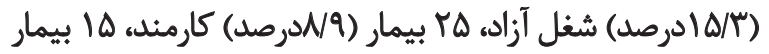

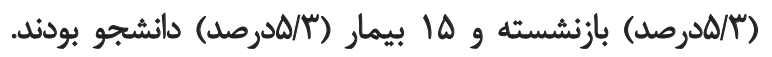

\section{درمانگاه بيمارستان روزبه}

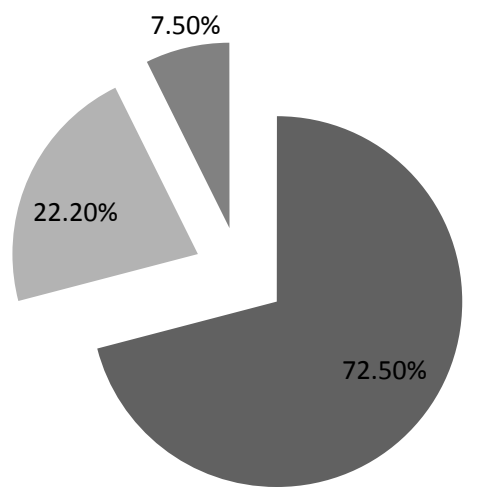

$$
\begin{aligned}
& \text { ص دمانعاه بزركسال } \\
& \text { | درمانكاه كودى و نوجوان } \\
& \text { درمانعاه مغز و اعصاب }
\end{aligned}
$$

\section{درمانگًاه كودك و نوجوان}

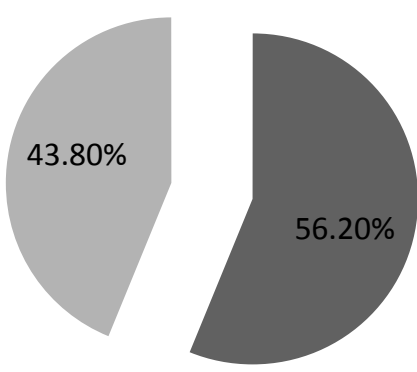

مراجعه

صدم مراجعه
درمانگًاه بزر كسال

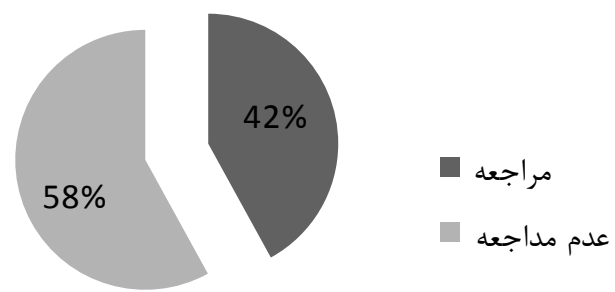


جدول r. تعيين رابطه نوع تشخيص با ميزان ريزش بيماران در درمانكاه بزركسال بيمارستان روزبه در بيكيرى يكساله.

\begin{tabular}{|c|c|c|c|c|}
\hline درصد ريزش & تعداد ريزش & درصد بيماران & تعداد بيماران & تشخيص \\
\hline$r / \Delta$ & $r$ & $\Delta / V$ & if & سايكوتيك \\
\hline$r / r$ & 9 & $\Delta / N$ & 18 & دوقطبي \\
\hline $9 / r^{2}$ & re & $\mid V / F$ & $p q$ & افسردكى \\
\hline$r / \Delta$ & $\checkmark$ & $\Delta / r^{\prime}$ & 10 & اضطراب \\
\hline W & r & $1 / 4$ & r & سوءمصرف مواد \\
\hline.$/ V$ & r & $1 / 4$ & $r$ & اختلالات جنسى \\
\hline $1 / f$ & f & $1 / \lambda$ & $\Delta$ & اختلال بيشفعالى وكمتمركزى \\
\hline.$/ 9$ & 1 &.$/ 4$ & 1 & اوتيسم \\
\hline$\cdot / \mathscr{H}$ & 1 &.$/ 6$ & 1 & اختلال تيك \\
\hline$Y / \Delta$ & $v$ & $r / A$ & $\wedge$ & اختلالات مغز و اعصاب \\
\hline.$/ 4$ & 1 & $M$ & r & افسردىى و اضطراب موارد ديكر \\
\hline$\mu / r$ & 9 & v/ & $r$. & افسردكى و اضطراب \\
\hline.$/ 4$ & 1 & $\cdot / V$ & r & 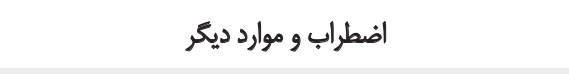 \\
\hline • & • &.$/ 4$ & 1 & افسردكى، سوءمصرف مواد، اختلال بيشفعالى و كمتمركزى \\
\hline $1 / 8$ & $r$ & $r / T$ & 9 & افسرد5ى و موارد ديكر \\
\hline.$/ p$ & 1 &.$\mu$ & 1 & دوقطبى و اخثلال بيشفعالى و كمتمركزى \\
\hline.$/ 9$ & 1 &.$/ V$ & r & اختلال بيش فعالى و كمتمركزى و موارد ديكر \\
\hline.$/ 4$ & 1 &.$/ N$ & r & اضطراب و اختلال بيشفعالى و كمتمركزى \\
\hline$\cdot$ & • & $\cdot / 4$ & 1 & افسردكى و اختلال بيشفعالى و كمثمركزى \\
\hline.$/ 4$ & 1 &.$/ 4$ & 1 & موقطبى و موارد ديكر \\
\hline.$/ F$ & 1 & $\cdot / F$ & 1 & افسردكى و سوءمصرف مواد \\
\hline $11 / \mathrm{V}$ & 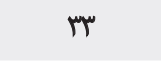 & $1 \Delta / V$ & fif & هوارد ديكر \\
\hline $1 \Delta / \pi$ & $r$ & reN & va & در برونده ثبت نشده است \\
\hline
\end{tabular}

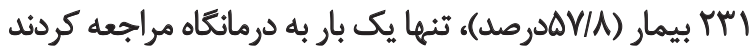

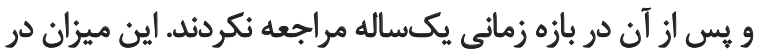

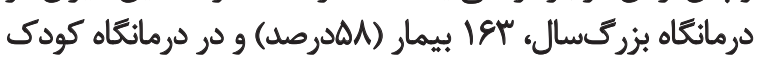

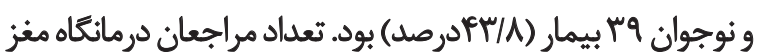

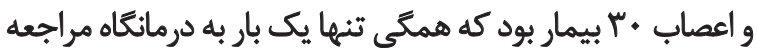

$$
\text { داشتئد. (تصوير شماره بار بود ) }
$$

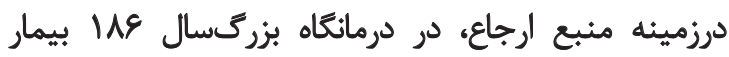

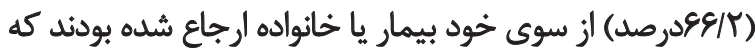

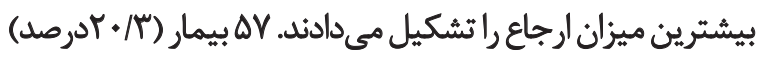

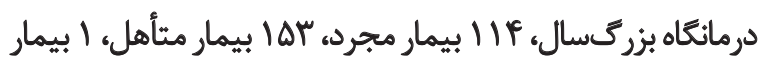

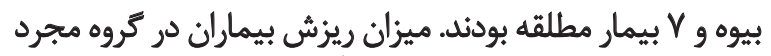

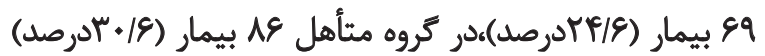

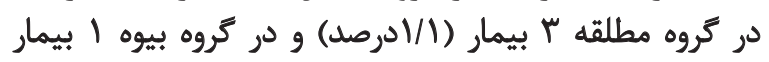

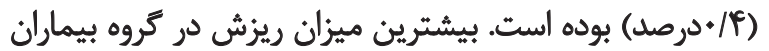

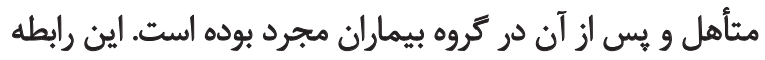

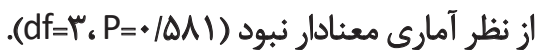

جدول شماره ا،ويثَّى هاى جمعيتشناختى مراجعان درمانكاه

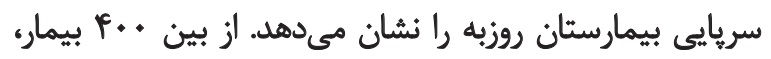


جدول F. تعيين رابطه نوع تشخيص با ميزان ريزش در درمائكاه كودك و نوجوان بيمارستان روزبه در بيكيرى يكساله.

\begin{tabular}{|c|c|c|c|c|}
\hline درصد ريزش & تعداد ريزش & درصد الفراد & تعداد الفراد & تشتحيص \\
\hline$\cdot$ & - & $1 / 1$ & 1 & سايكوتيك \\
\hline - & - & $r / T$ & r & دوقطبيى \\
\hline $1 / 1$ & 1 & $r / \Delta$ & f & اضطراب \\
\hline 1.11 & q & TV & mf & اختالال بيش فعاليى و كمتمركزى \\
\hline$m / s$ & r & $\Delta / 8$ & $\Delta$ & 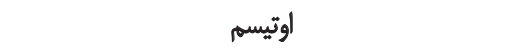 \\
\hline - & • & $1 / 1$ & 1 & افسردكى و اضطراب \\
\hline $1 / 1$ & 1 & $1 / 1$ & 1 & اضطراب و موارد ديكر \\
\hline • & - & $1 / 1$ & 1 & اضطراب و اوتيسم \\
\hline$r / r$ & r & $\Delta / \&$ & $\Delta$ & دوقطبى و اختلال بيشفعالى و كمتمركزى \\
\hline$r / \Delta$ & f & $\mid f / 8$ & ir & اختلال بيشفعالى و كمتمركزى و موارد ديكر \\
\hline • & • & $r / r$ & r & اختلال ييشفعالى و كمتمركزى و اوتيسم و موارد ديكر \\
\hline $1 / \Delta$ & f & $V / 9$ & 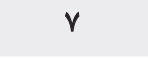 & اضطراب و اختلال بيش فعالى و كمتمركزى \\
\hline - & - & $1 / 1$ & 1 & افسردكى و اختلال بيش فعالى و كمتمركزى \\
\hline $1 / 1$ & 1 & $1 / 1$ & 1 & اضطراب و اختلال بيش فعالى و كمتمركزى و وتيسم \\
\hline • & $\cdot$ & $1 / 1$ & 1 & اختلال بيش فعالى و كمتمركزى و تيك \\
\hline Ir/F & 11 & $\mid r / \varphi$ & 11 & موارد ديكر \\
\hline$m / \varphi$ & r & $1 . / 1$ & 9 & در يرونده ثبت نشده است \\
\hline
\end{tabular}

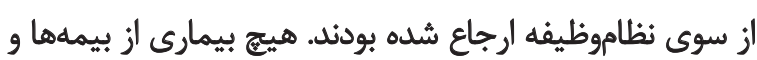

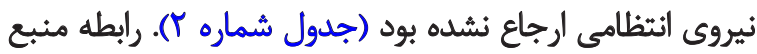

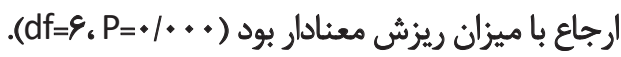

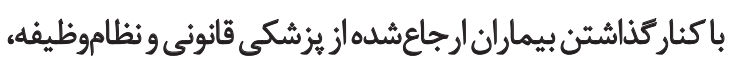

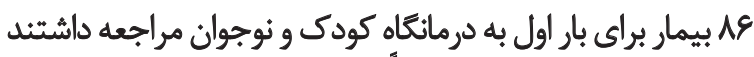

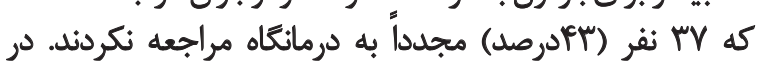

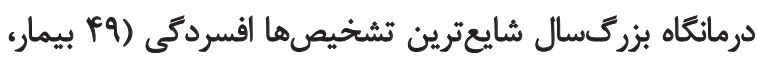

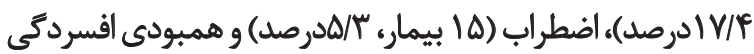

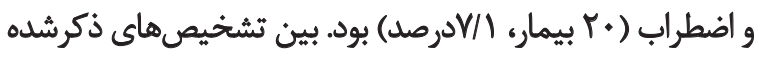

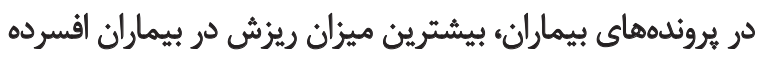

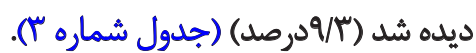

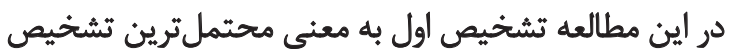

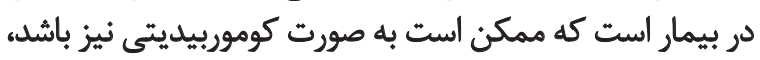

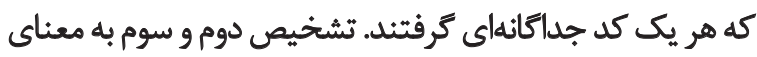

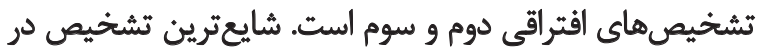

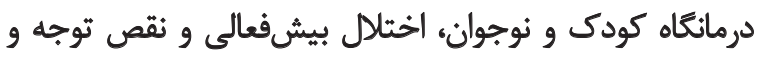

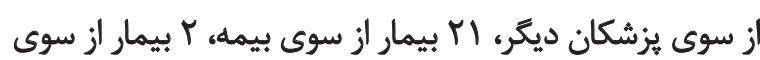

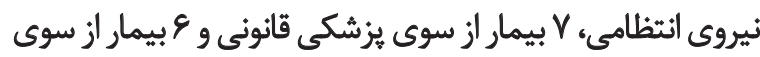

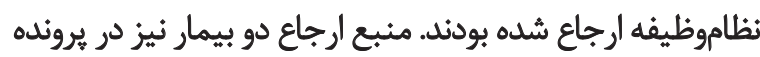

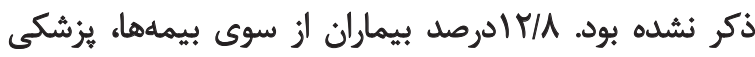

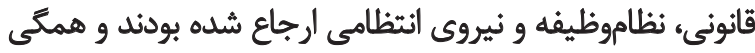

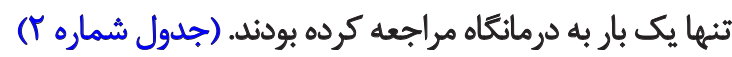

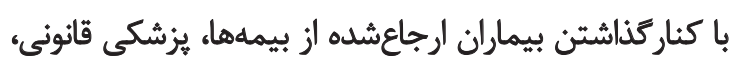

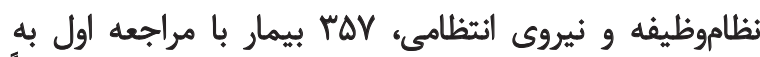

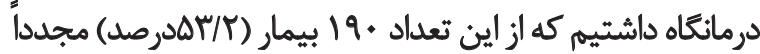

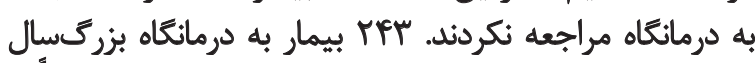

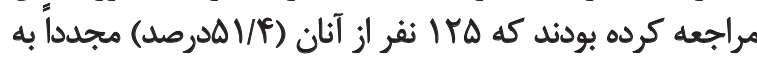

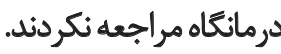

درزمينه منبع ارجاع در درمائكاه كودى و نوجوان، بهأ بيمار

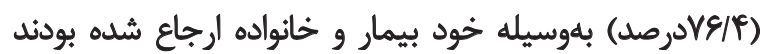

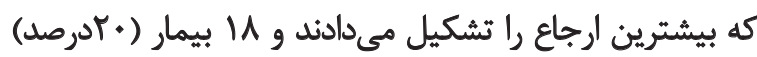

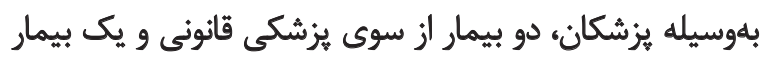


دV\&/F

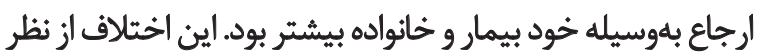
آمارى معنادار بود.

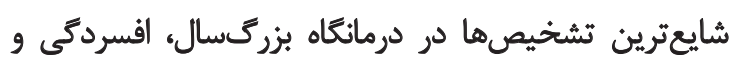

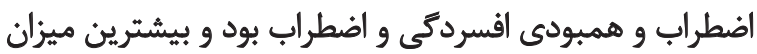

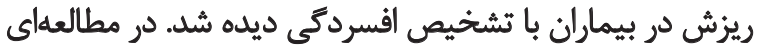

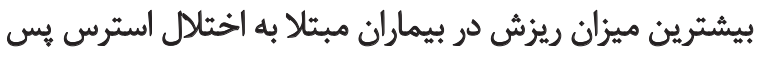

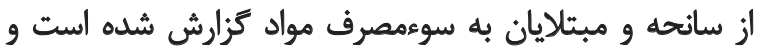

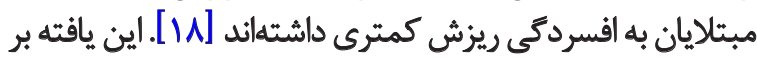

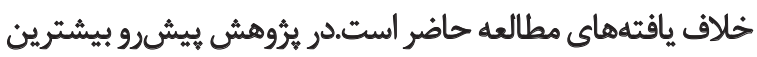

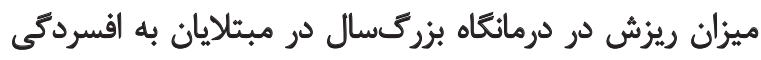

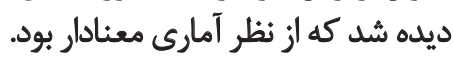

در مطالعهاى كه ميزان ريزش بيماران افسرده در درمانعاه

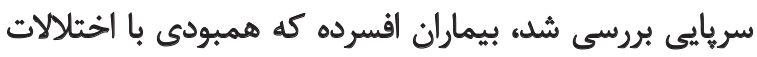

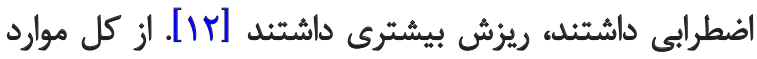

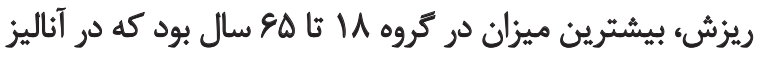

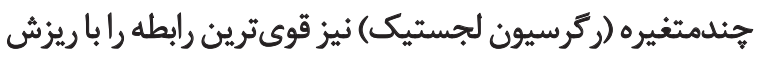

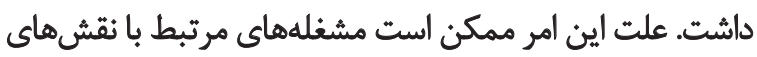

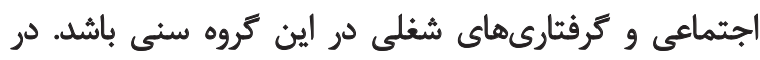

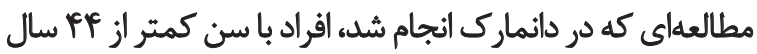

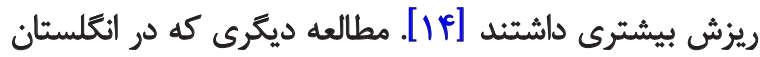

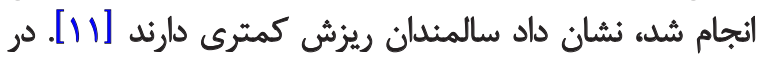

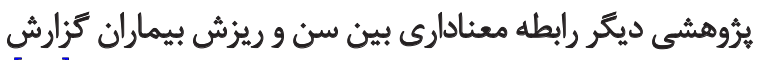

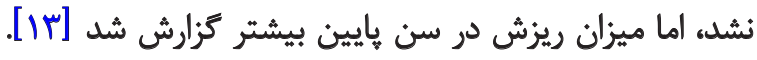

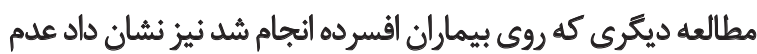

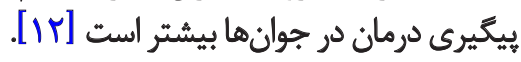

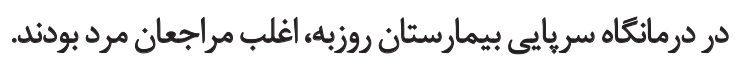

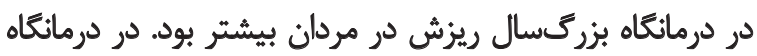

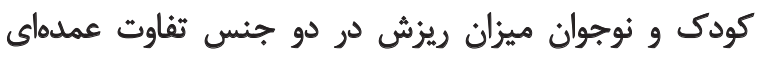

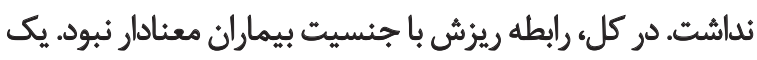

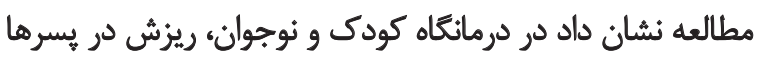

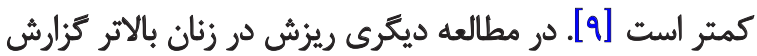

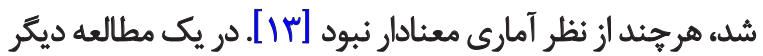

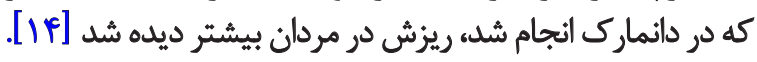

در مراجعان به درمانكاه بزرگ برسال بيمارستان روزبه، تحصيلات

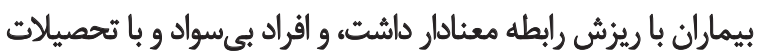

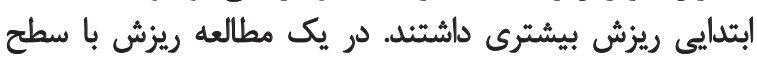

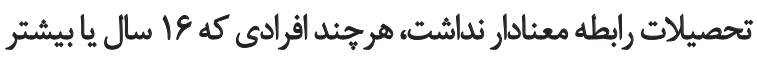

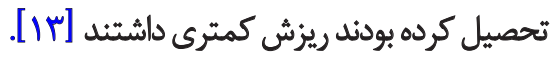

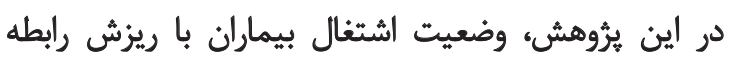

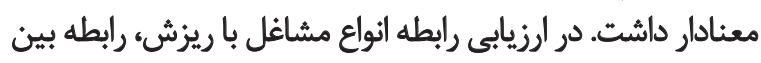
بازنشستى و ريزش معنادار بود كه ممكن است وضعيت مالى بارئى رابط بين

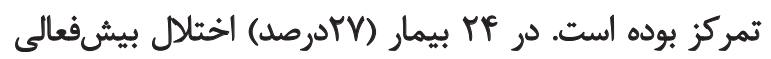

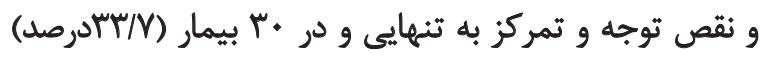

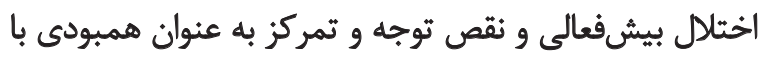

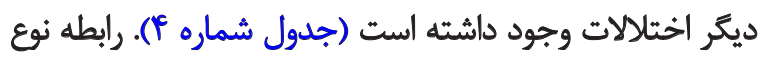

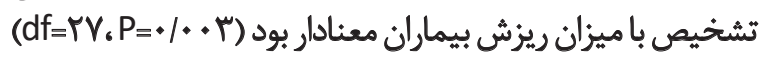

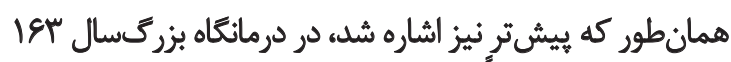

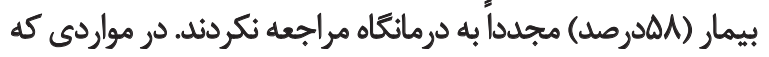

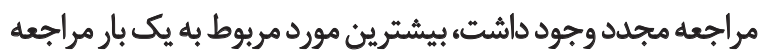

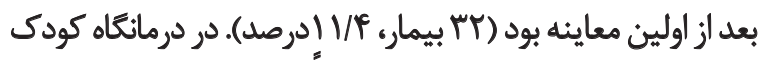

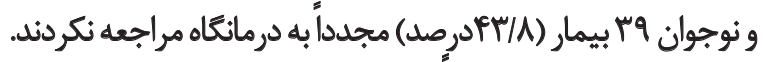

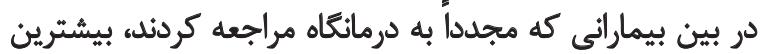

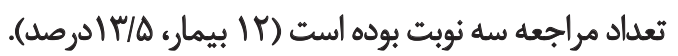

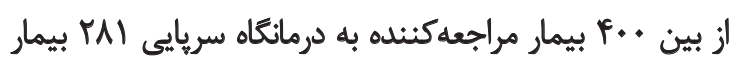

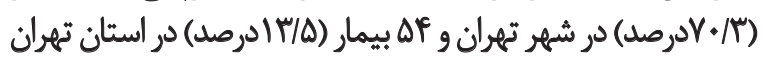

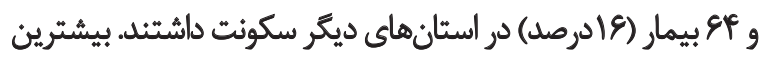

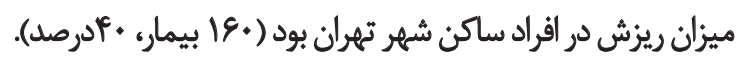

بحث

اين مطالعه با هدف تعيين ميزان ريزش در درمانكاه سريايي

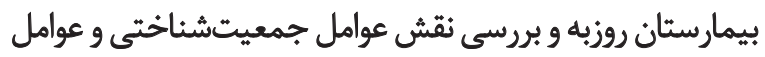

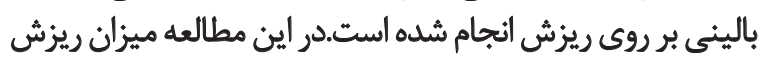

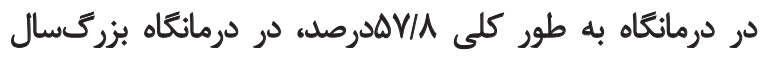

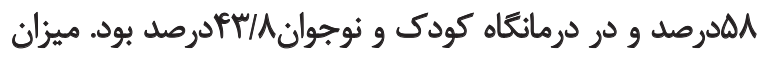

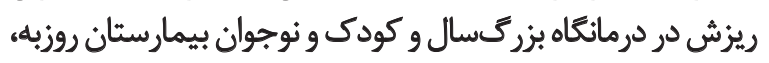

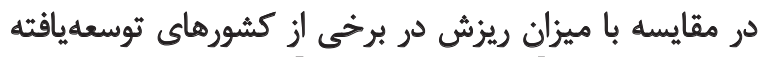

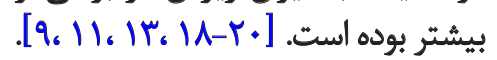

در كشورهاي درحالتوسعه اطلاعات محدودترى در دسترس

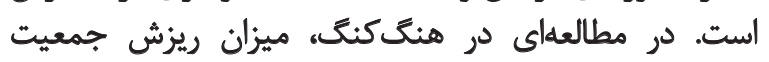

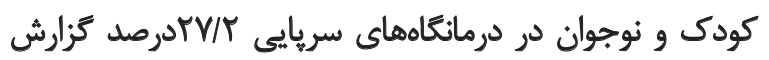

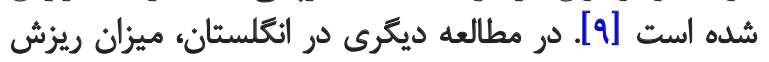

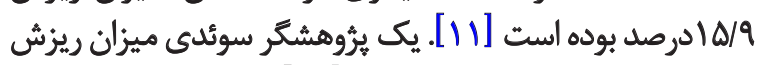

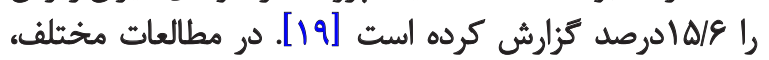

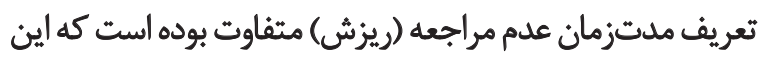

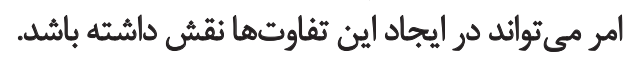

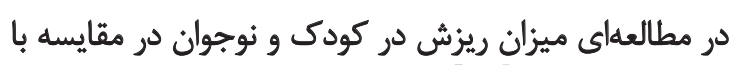

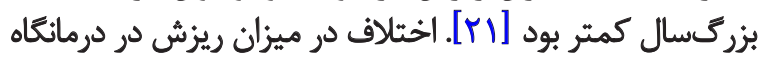

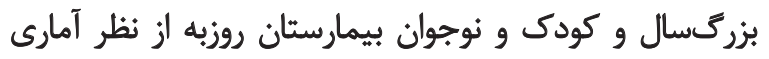

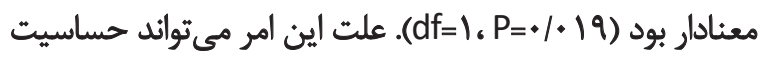

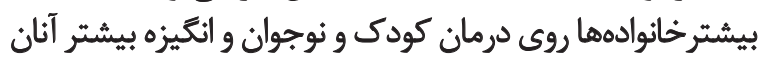

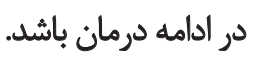

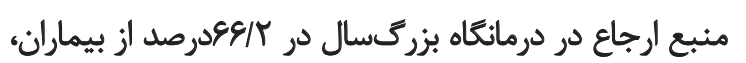

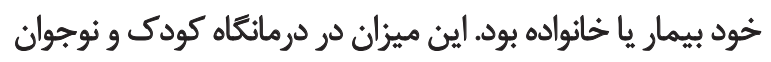


آن ديكر براى بيعيرى درمان مراجعه نمي كنئد. اين امر اهميت

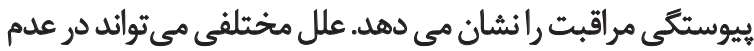

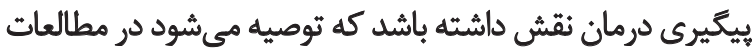

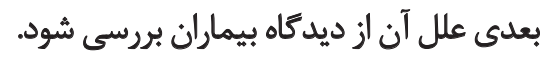

لازم است مداخلاتى براى كاهش ميزان ريزش بيمار بران، بهويرُّه

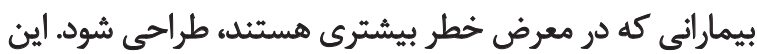

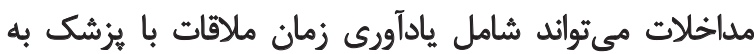

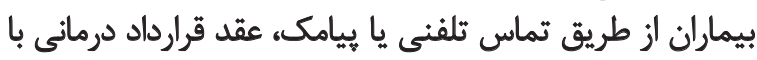

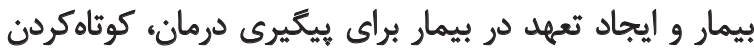

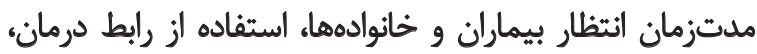

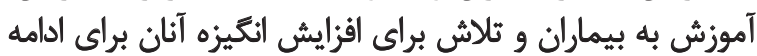

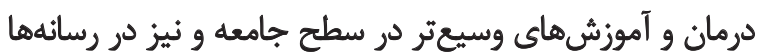

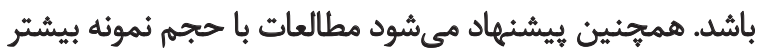

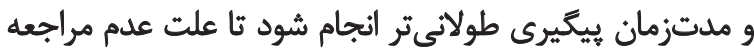

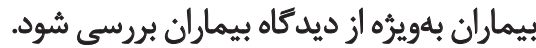

$$
\text { سياسكرًارى }
$$

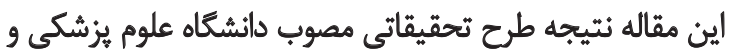

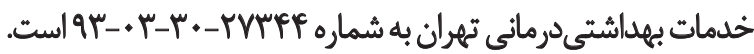
[بنا به اظهار نويسنده مسئول مقاله، تعارض منافع وجود نداشته

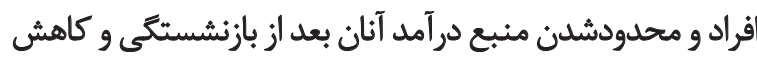
انكيزههاى آنان بعد از اين دوران در اين امر نقش داشئه باند باشد.

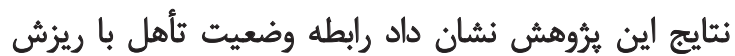

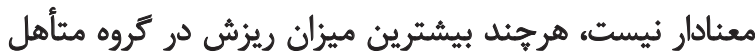

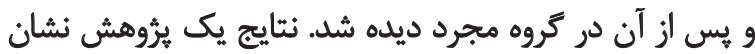

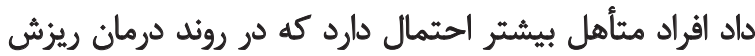

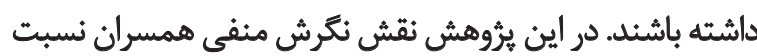

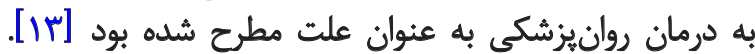

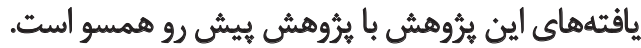

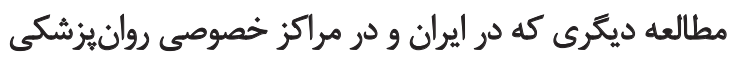

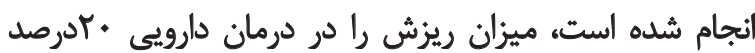

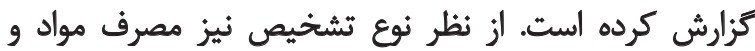

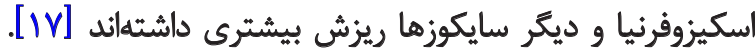

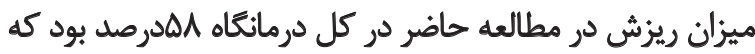

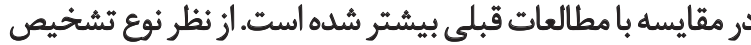

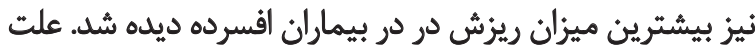

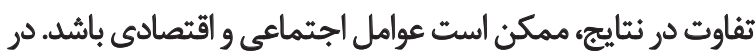

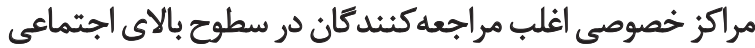

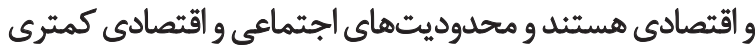

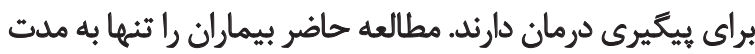

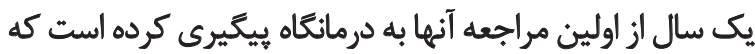
از محدوديتهاي اين مطالعه است و لازم است در مطالعات بعدى برى بردي

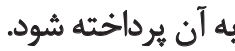

مطالعه حاضر محدوديتهايي داشته است، ازجمله مي توتوان به

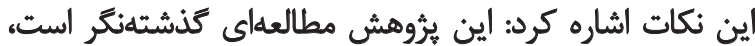

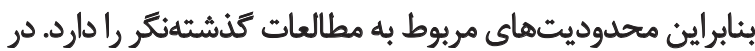

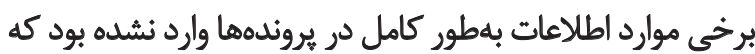

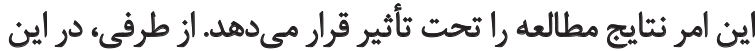

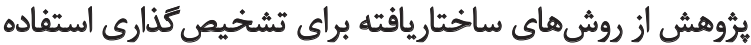

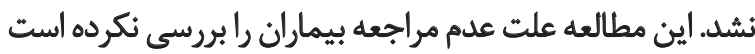

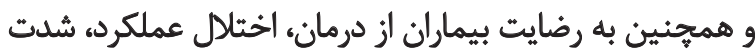

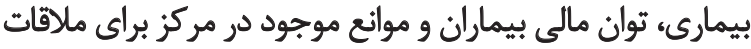

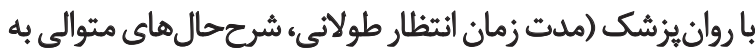

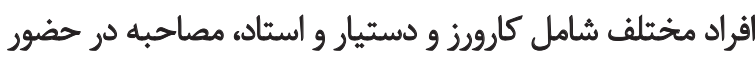

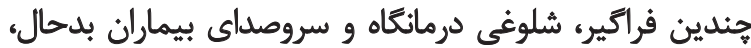

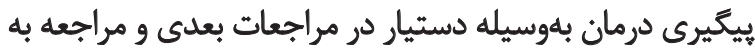

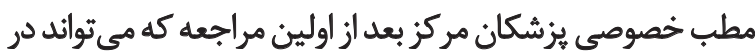

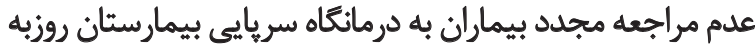
براى بيكيرى درمان مؤثر باشد) نيرداخته است دمانت

نتيجهيَيرى

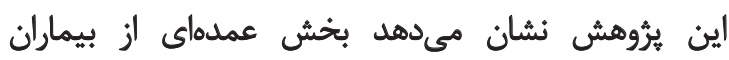

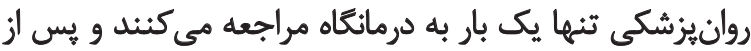




\section{References}

[1] Baumeister H, Härter M. Prevalence of mental disorders based on general population surveys. Social Psychiatry \& Psychiatric Epidemiology. 2007; 42(7):537-46. doi: 10.1007/s00127-007-0204-1

[2] Sharifi V, Daliri S, Amini A, Mohammadi M. [Psychiatric Problems in General Outpatient Clinics: Prevalence and Reasons for Help Seeking (Persian)]. Iranian Journal of Psychiatry Clinical Psychology. 2011; 16(4):484-489.

[3] Sharifi V, Amin-Esmaeili M, Hajebi A, Motevalian A, Radgoodarzi R, Hefazi M, et al. Twelve-month prevalence and correlates of psychiatric disorders in Iran: The Iranian Mental Health Survey, 2011. Archive of Iranian Medicine. 2015; 18(2):76-84. doi: 015182/AIM.004

[4] Sharifi V, Daliri S, Amini H, Mohammadi M. [Psychiatric problems in general outpatient clinics: Prevalence and reasons for help seeking (Persian)]. Iranian Journal of Psychiatry \& Clinical Psychology. 2011; 16(4):484-489

[5] Codony M, Alonso J, Almansa J, Bernert S, de Girolamo G, de Graaf $R$, et al. Perceived need for mental health care and service use among adults in Western Europe: Results of the ESEMeD Project. Psychiatric Services. 2009; 60(8):1051-58. doi: 10.1176/ ps.2009.60.8.1051

[6] Wang J. Mental health treatment dropout and its correlates in a general population sample. Medical Care. 2007; 45(3):224-9. doi: 10.1097/01.mlr.0000244506.86885.a5

[7] Wang PS, Aguilar-Gaxiola S, Alonso J, Angermeyer MC, Borges $\mathrm{G}$, Bromet EJ, et al. Use of mental health services for anxiety, mood, and substance disorders in 17 countries in the WHO world mental health surveys. Lancet. 2007; 370(9590):841-50. doi: 10.1016/s0140-6736(07)61414-7

[8] Adeponle AB, Baduku AS, Adelekan ML, Suleiman GT, Adeyemi SO. Prospective study of psychiatric follow-up default and medication compliance after discharge at a psychiatric hospital in Nigeria. Community Mental Health Journal. 2008; 45(1):19-25. doi: 10.1007/s10597-008-9155-6

[9] Lai K, Pang A, Wong CK, Lo MK, Lum F. Outcome and characteristics of dropouts from a child and adolescent psychiatry clinic in Hong Kong. European Psychiatry. 1996; 11:320. doi: 10.1016/0924-9338(96)88995-4

[10] Berghofer G, Schmidl F, Rudas S, Steiner E, Schmitz M. Predictors of treatment discontinuity in outpatient mental health care. Social Psychiatry and Psychiatric Epidemiology. 2002; 37(6):27682. doi: $10.1007 / \mathrm{s} 001270200020$

[11] Mitchell AJ, Selmes T. A comparative survey of missed initial and follow-up appointments to psychiatric specialties in the United Kingdom. Psychiatric Services. 2007; 58(6):868-71. doi: $10.1176 /$ ps.2007.58.6.868

[12] Arnow BA, Blasey C, Manber R, Constantino MJ, Markowitz JC, Klein DN, et al. Dropouts versus completers among chronically depressed outpatients. Journal of Affective Disorders. 2007; 97(1-3):197-202. doi: 10.1016/j.jad.2006.06.017

[13] Olfson M, Mojtabai R, Sampson N, Hwang I, Druss B, Wang $\mathrm{P}$, et al. Dropout from outpatient mental health care in the united states. Psychiatric Services. 2009; 60(7):898-907. doi: 10.1176/appi. ps.60.7.898
[14] Munk-Jørgensen P, Andersen B. Diagnoses and dropout among patients of Danish psychiatrists in private practice. Psychiatric Services. 2009; 60(12):1680-2. doi: 10.1176/appi.ps.60.12.1680

[15] McFarland BR, Klein DN. Mental health service use by patients with dysthymic disorder: Treatment use and dropout in a 71/2year naturalistic follow-up study. Comprehensive psychiatry. 2005;46(4):246-53. doi: 10.1016/j.comppsych.2004.10.002

[16] Tehrani E, Krussel J, Borg L, Munk-Jorgensen P. Dropping out of psychiatric treatment: A prospective study of a first-admission cohort. Acta Psychiatrica Scandinavica. 1996; 94(4):266-71. doi: 10.1111/j.1600-0447.1996.tb09859.x

[17] Khazaie H, Rezaie L, de Jong DM. Dropping out of outpatient psychiatric treatment: a preliminary report of a 2-year followup of 1500 psychiatric outpatients in Kermanshah, Iran. General Hospital Psychiatry. 2013; 35(3):314-9. doi: 10.1016/j.genhosppsych.2012.10.008

[18] Sparr LF, Moffitt MC, Ward MF. Missed psychiatric appointments: who returns and who stays away. American Journal of Psychiatry. 1993; 150(5):801-5. doi: 10.1176/ajp.150.5.801

[19] Johansson H, Eklund M. Helping alliance and early dropout from psychiatric out-patient care. Social Psychiatry \& Psychiatric Epidemiology. 2006; 41(2):140-7. doi: 10.1007/s00127-005-0009-z

[20] Lerner Y, Levinson D. Dropout from outpatient mental health care: results from the Israel National Health Survey. Social Psychiatry \& Psychiatric Epidemiology. 2011; 47(6):949-55. doi: 10.1007/s00127-011-0402-8

[21] Block AM, Greeno CG. Examining Outpatient Treatment Dropout in Adolescents: A literature review. Child \& Adolescent Social Work Journal. 2011; 28(5):393-420. doi: 10.1007/s10560011-0237-x

[22] Alagheband Rad J, Naghavi HR, Shahrivar Z, Hakim Shooshtari M, Shirazi E, Mohammadi MR, et al. [An epidemiological study of psychiatric disorders in children and adolescents 6 to 18 years old (Persian)]. Tehran: National Research Center of Medical Sciences; 2000. 